\title{
Agroecologia: experiência em construção no contexto do Desenvolvimento Regional
}

\author{
Agroecology: acquiring experience in the context of regional development
}

\author{
Erica Karnopp \\ Universidade de Santa Cruz do Sul - Santa Cruz do Sul - Rio Grande do Sul - Brasil \\ ORCID https://orcid.org/0000-0001-5976-2331
}

Jaime Miguel Weber

Universidade de Santa Cruz do Sul - Santa Cruz do Sul - Rio Grande do Sul - Brasil ORCID https://orcid.org/0000-0002-2335-0295

Resumo: Neste artigo analisa-se a base teórica da agroecologia e o conhecimento empírico, com ênfase na agricultura familiar. Buscou-se estabelecer uma relação dessa base teórica com o conhecimento empírico em unidade familiar agrícola do município de Santa Cruz do Sul, RS/Brasil. As tendências mundiais mostram que a agricultura convencional ainda tem preferência, embora o desenvolvimento da agricultura de base ecológica, nos últimos anos, tenha crescido consideravelmente. A continuidade do desenvolvimento da agricultura de base ecológica depende do aumento pela procura por produtos orgânicos, por um lado, e por outro, de uma nova reestruturação da comercialização, bem como da organização dos agricultores familiares e da criação de políticas públicas para esse fim. Resultados positivos para o desenvolvimento sustentável dependem muito do desenvolvimento adequado e combinado da produção, industrialização e comercialização da produção, bem como das formas de organização e engajamento dos "atores sociais", mas, sobretudo do planejamento da sociedade regional sobre o seu futuro.

Palavras-chave: Agroecologia, agricultura ecológica, agricultura orgânica.

Abstract: This article analyzes agroecology's theoretical background and empirical knowledge, emphasizing family farming. A relation between this theoretical background and the empirical knowledge was sought in a family farm within the municipality of Santa Cruz do Sul, state of Rio Grande do Sul, Brazil. Global trends show that conventional agriculture is still preferred, despite the considerable growth of ecologybased agriculture in the last few years. The ongoing development of ecology-based agriculture relies, on one hand, on the rise of demand for organic products, and on the other hand, on restructuring commercialization and the organization of family farmers, as well as creating public policies with this objective. Positive results for sustainable development depend heavily on adequate and combined development of production, 
industrialization and commercialization of produce, as well as the development of forms of organization, the engagement of the "social actors" and especially Regional Society's planning regarding its future.

Keywords: Agroecology, ecological agriculture, organic agriculture.

\section{Introdução}

Significativas mudanças têm ocorrido no espaço rural brasileiro nas últimas décadas, com alterações expressivas na base técnica de produção, na dinâmica de vida das pessoas, na relação com o ambiente, e na produção e transformação de alimentos, basicamente em função da busca pelo aumento da produção e produtividade. Esse modelo de "modernização" da agricultura, também conhecido como Revolução Verde, efetivado com mais ênfase a partir dos anos 1960 passou a desencadear muitas consequências, especialmente para o meio ambiente e para os agricultores de base familiar, como o êxodo rural, a concentração de terras, a perda da biodiversidade, a contaminação do homem e dos recursos naturais. Ehlers (1996) comenta que esse modelo se espalhou por vários países, quase sempre com apoio de órgãos governamentais, pela grande maioria da comunidade agronômica e pelas empresas produtoras de insumos "Também tiveram destacada participação nesse processo várias organizações internacionais como o Banco Mundial, o Banco Interamericano de Desenvolvimento (BID), United States Agency for Intenational Development (USAID Agência norte-americana para o desenvolvimento internacional), a Organização das Nações Unidas para a Agricultura e a Alimentação (FAO), dentre outras". Enfim, esse modelo transformou totalmente as relações de produção no campo.

Nas últimas décadas o tema da fome tem sido motivo de muita preocupação de governos, organizações sociais e organismos multilaterais. A discussão sobre segurança e soberania alimentar e o tratamento como algo de maior amplitude e complexidade tem acontecido com maior ênfase nos últimos anos, pela compreensão necessária sobre tudo o que envolve este tema, especialmente na busca da integração das agendas econômica, social e ambiental.

Segundo a FAO (2014), o conceito consagrado nos documentos diz que "existe segurança alimentar sempre que todas as pessoas tenham acesso físico e econômico a alimentos suficientes, seguros e nutritivos que atinjam suas necessidades alimentares e preferências alimentares para uma vida ativa e saudável".

A agricultura familiar é uma prática histórica e o conhecimento tradicional de práticas e sistemas de produção com base nos princípios da agroecologia, ou de outros sistemas menos agressivos ao ambiente, têm contribuído nos debates sobre os paradigmas e os rumos do desenvolvimento. Infelizmente, a agricultura familiar de base ecológica ainda possui certa invisibilidade em relação aos processos socioculturais e 
econômicos dos territórios. Nos últimos anos esse tema tem aparecido nas agendas e nos debates regionais, mas pouco se tem avançado no sentido do reconhecimento e da efetivação de políticas públicas inclusivas para esse setor.

Assim, ao estudar os rumos da agricultura, em especial da agricultura familiar, passamos a perceber um conjunto de questões intrinsecamente ligadas a aspectos sociais, políticos, ambientais, e culturais, que ao longo da história vão influenciando as dinâmicas sociais e a vida das pessoas nos territórios.

\section{Conhecimento empírico}

Este artigo é resultado do convívio e reflexões sobre a experiência de produção de base ecológica de frutas e hortaliças, realizada pelo agricultor Persi Frantz, residente na comunidade de Monte Alverne, Distrito do município de Santa Cruz do Sul - RS/Brasil. A análise desta experiência foi realizada a partir de visitas na propriedade, tomando como fonte de dados a observação das atividades produtivas e diálogos com o agricultor sobre a sua história e o desenvolvimento do sistema de produção ao longo dos anos.

Há um conjunto de termos que são utilizados para conceituar ou explicar os distintos (novos) modos de produção menos agressivos ao ambiente, com a utilização de distintas designações como ecológica, natural, orgânica, regenerativa, biodinâmica, permacultura, entre outras. Para CAPORAL, COSTABEBER (2008) o uso do termo Agroecologia nos tem apresentado a ideia e a perspectiva de uma nova agricultura capaz de fazer bem ao homem e ao meio ambiente. Sendo assim, são corriqueiras as interpretações que associam a Agroecologia com "uma vida mais saudável"; "uma produção agrícola dentro de uma lógica em que a natureza mostra o caminho"; "uma agricultura socialmente justa"; "o ato de trabalhar dentro do meio ambiente, preservando-o"; "o equilíbrio entre nutrientes, solo, planta, água e animais"; "o continuar tirando alimentos da terra sem esgotar os recursos naturais"; "um novo equilíbrio nas relações homem e natureza"; "uma agricultura sem destruição do meio ambiente"; "uma agricultura que não exclui ninguém"; entre outras.

\footnotetext{
Quando se fala de Agroecologia, está se tratando de uma orientação cujas contribuições vão muito além de aspectos meramente tecnológicos ou agronômicos da produção, incorporando dimensões mais amplas e complexas, que incluem tanto variáveis econômicas, sociais e ambientais, como variáveis culturais, políticas e éticas da sustentabilidade. (CAPORAL, COSTABEBER, 2008, p. 13)
}

Devemos considerar que nas últimas décadas tivemos vários avanços em distintos tipos de agriculturas menos agressivas ao ambiente. Nesse sentido, temos avançado significativamente em quantidade de agricultores e volumes de produção, tanto a produção familiar de base ecológica, como a entrada de grandes grupos transnacionais que estão se apropriando do mercado orgânico pela crescente possibilidade de espaços de comercialização e especialmente de lucro imediato. Para Caporal (2008) não se deve entender como agricultura baseada nos princípios da 
Agroecologia aquela agricultura que, simplesmente, não utiliza agrotóxicos ou fertilizantes químicos de síntese em seu processo produtivo. Considerando que nem todas as escolas ou correntes da agricultura (menos danosas ao ambiente) se utilizam dos princípios da agroecologia. Não se trata apenas da substituição de insumos químicos por insumos orgânicos.

Outro termo que passou a ser utilizado com mais frequência a partir dos anos 1980 é o agroecossistema como forma de reconhecer e considerar a prática da agricultura como um sistema de produção, com uma gama de interações que deve ser tratada em seu conjunto - enfoque holístico e sistêmico. Para Altieri (1989) Agroecossistema é a unidade essencial de estudo, nos quais os ciclos minerais, as alterações energéticas, os processos biológicos e as relações socioeconômicas precisam ser vistas e analisadas em seu conjunto. Sob o ponto de vista da pesquisa agroecológica, seus objetivos não são a maximização da produção de uma atividade particular, mas a otimização do agroecossistema como um todo, o que significa a necessidade de uma maior evidência no conhecimento, na análise e na interpretação das complexas relações existentes entre as pessoas, os cultivos, o solo, a água e os animais.

\footnotetext{
Sendo assim, a Agroecologia, a partir de um enfoque sistêmico, adota o agroecossistema como unidade de análise, tendo como propósito, em última instância, proporcionar as bases científicas (princípios, conceitos e metodologias) para apoiar o processo de transição do atual modelo de agricultura convencional para estilos de agriculturas sustentáveis. (CAPORAL, COSTABEBER 2008, p. 11, p. 12).
}

Uma das "portas de entrada" para vários pesquisadores tem sido o reconhecimento do conhecimento local/saber popular como uma importante referência para a construção de conhecimento e "diálogo" entre saberes, o empírico (local) e o científico. Para Gliessman (2000), a abordagem agroecológica pode ser determinada como "a aplicação dos princípios e conceitos da Ecologia no manejo e desenho de agroecossistemas sustentáveis", num horizonte temporal, partindo do conhecimento local que, integrando ao conhecimento científico, dará lugar à construção e ampliação de novos saberes socioambientais, subsidiando de forma permanente, o processo de transição agroecológica.

A legislação para regulamentação da produção orgânica no país, após ampla discussão entre os setores envolvidos (governo, produtores, associações, cooperativas, pequenos agricultores, técnicos,...) teve sua arrancada com a elaboração da Lei $\mathrm{n}$ ㅇ 10.831 de 23 de dezembro de 2003, regulamentada pelo Decreto no 6.323 de 27 de dezembro de 2007.

A legislação que regulamenta a produção orgânica entrou em vigor em 01/01/2011, desde lá todo produtor deve estar vinculado a uma Organização de Controle Social - OCS, um Organismo Participativo de Avaliação da Conformidade OPAC, para ter acesso a certificação participativa a partir de regras específicas. Ou então buscar uma certificadora credenciada para obter o selo de produtor orgânico, para comercializar produto com o reconhecimento da qualidade orgânica. O Cadastro 
Nacional de Produtores Orgânicos (CNPO) é mantido pelo MAPA, e possui informações sobre os produtores, produtos e organismos responsáveis pelo acompanhamento, controle e informação da qualidade orgânica. No início de 2012 o RS possuía em torno de 700 unidades de produção controladas, em sua maioria agricultores, mas contemplando também processadores. De lá para cá o estado tem apresentado um crescimento constante e os dados disponíveis na última atualização do CNPO, de 30/11/2017, indicam a existência de 2092 Unidades de Produção Controlada - UPCs, sendo que o Estado do Paraná é o primeiro com 2405 UPCs. Das UPCs gaúchas 1322 são vinculados aos OPACs e OCSs, demonstrando o acerto da lei aprovada em dezembro de 2003 em inovar e regulamentar pela primeira vez no mundo os formatos participativos na garantia da qualidade orgânica.

Em termos geográficos a concentração das UPCs se dá em regiões onde houve processo de colonização e mais recentemente de reforma agrária, ou seja, na serra gaúcha em cidades próximas a Caxias do Sul, na região metropolitana de Porto Alegre, Vale do Caí, e Zona Sul do Estado, especialmente nos municípios próximos a Pelotas, também se destaca a região da Campanha devido ao expressivo número de Assentamentos.

No início do processo organizativo a produção orgânica tinha como centralidade as frutas e hortaliças, com ênfase nos circuitos curtos de comercialização (mercado local). Nos últimos anos a produção tem se diversificado para produtos de origem animal, plantas comestíveis não convencionais, e frutas nativas. Ou seja, um resgate e (re)valorização de espécies de plantas, normalmente nativas das regiões, com potencial nutritivo.

A transição de uma agricultura convencional para a ecológica norteia-se num processo gradual de mudança, através do tempo, nas formas de manejo dos agroecossistemas, tendo como meta a passagem de um modelo agroquímico de produção a um modelo ou estilo de agricultura que incorpore princípios, métodos e tecnologias com base ecológica.

A ideia de base ecológica se refere a um processo de evolução contínua, multilinear e crescente no tempo, porém sem ter um momento final determinado. Por se tratar de um processo social, isto é, por depender da intervenção e da interação humana, a transição agroecológica implica não somente a busca de uma maior racionalização econômica e produtiva com base nas especificidades biofísicas de cada ecossistema, mas também uma mudança nas atitudes e valores dos atores sociais em relação ao manejo e conservação dos recursos naturais. Por incluir considerações de natureza diversa (econômica, cultural, social, política, ambiental, entre outras), o processo de transição agroecológica não dispensa o progresso técnico e o avanço do conhecimento científico (COSTABEBER, 1998, p.25).

Com o objetivo de realizar uma análise empírica detalhada, foi selecionada uma propriedade agrícola que desenvolve práticas de base ecológica, localizada na Linha São Martinho, Distrito de São Martinho, município de Santa Cruz do Sul. O município 
pertenceu à colônia de Santa Cruz, que foi fundada em 1849 por imigrantes alemães. Neste sentido, segue o detalhamento da unidade familiar de base ecológica.

a) História pessoal

Perci Darcísio Frantz tem sua origem na agricultura familiar, é filho de agricultores familiares. A propriedade está localizada na comunidade de São Martinho, Distrito de Monte Alverne, município de Santa Cruz do Sul. A área de 23,7 hectares é de propriedade da família, e destes, ha estão sob a gestão do Sr. Perci, onde tem desenvolvido sua produção de base ecológica. A estimativa é que mais da metade do total da área da propriedade é coberta por uma composição de mata nativa e eucalipto. Considera que a propriedade (comunidade) possui características diferenciadas de clima, comparada com outras comunidades do município de Santa Cruz do Sul, por estar localizada numa área de mata atlântica, que ainda mantém uma área aproximada de 220 hectares de floresta, na comunidade. Relata que depois de completar 18 anos, e após concluir o serviço militar, passou a ter contato com o tema da produção ecológica, através da igreja, o que despertou curiosidade, interesse e motivação, "escutei algumas falas sobre produzir sem a utilização de venenos e adubos químicos; fiquei motivado, no entanto, era difícil encontrar alguém que eu pudesse ao menos conversar, sem que me considerasse louco", comenta Perci.

b) Sistema de produção

As primeiras informações sobre produção ecológica, além de despertar curiosidade e motivação, serviram para tomar a decisão de iniciar a produção de base ecológica. No início, a disposição foi de transformar tudo em produção ecológica, ou seja, banir o uso de agroquímicos. O fato de ainda não possuir muito conhecimento sobre esse tipo de sistema de produção, de não dominar as técnicas, e de não ter experiência em gestão da produção, a primeira tentativa foi fracassada; "dei com os burros na água, quebrei", reconhece Perci. Esse "fracasso" fez com que voltasse a trabalhar na cidade. Essa volta à cidade não significou uma desistência permanente, tanto que continuou a buscar informações. Na sequência de idas e vindas, da cidade para a propriedade, outras duas tentativas também não foram exitosas.

Com o tempo percebeu que essa mudança do sistema convencional para o de base ecológica deveria ser gradativa, e deveria ser trabalhada como um processo de transição, com muita observação sobre as reações e respostas da natureza. Em 2007 retornou para a propriedade, onde fez uma parceria com a família. Da área total de 23,7 hectares, a família concordou em disponibilizar espaços para o desenvolvimento de lavouras "experimentais". E foi assim, de forma progressiva que alguns pequenos espaços foram sendo ocupados e trabalhados com base nos princípios da agroecologia. $\mathrm{Na}$ definição desses espaços, alguns critérios foram sendo levados em consideração, como o aproveitamento de materiais que estavam disponíveis na propriedade e espaços que pudessem de certa forma, ficarem isolados dos cultivos convencionais, como o tabaco. 
Dessa forma, esses pequenos espaços foram sendo ampliados até chegar a uma área de 2,77 hectares. A primeira experiência realizada nesses espaços foi com a produção de cultivos anuais - folhosas, rabanete, beterraba, cenoura, chuchu, feijões, entre outras. Na sequência foi ampliado o cultivo de banana, com a utilização de mudas já existentes na propriedade, inicialmente consorciada com chuchu, de maneira experimental. Então, os primeiros aprendizados foram com a produção de banana consorciada com chuchu. Contido, a ideia inicial era utilizar o cultivo da banana como quebra-vento para os cultivos anuais, especialmente para a produção de chuchu (em forma de parreiral) e também como produção de frutas. Outra técnica utilizada para evitar o revolvimento do solo e para aumentar os níveis de matéria orgânica foi o manejo de plantas espontâneas (manter o solo coberto, ter indicação do desenvolvimento do solo - bioindicador, recuperar deficiência de nutrientes, aumentar teor de matéria).

Os recursos obtidos da comercialização da banana e do chuchu foram utilizados para a recuperação de um pomar de citros, com 2,62 hectares, que se encontrava em situação precária, sem manejo adequado, desequilibrado, e com produção e produtividade muito baixas. Tanto é verdade que a recomendação técnica, na época, era de realização de poda drástica ou a implantação de um novo pomar. Posteriormente passou a utilizar técnicas semelhantes para a recuperação do pomar de citros, a partir de um processo de transição da produção convencional para a de base ecológica. Inicialmente, a utilização de alguns produtos foi crucial para a implantação dos sistemas de produção, como composto orgânico, esterco animal, biofertilizante e caldas a base de cobre e enxofre, uso de cinzas, além do manejo do solo, com a utilização de algumas técnicas de recuperação, como a roçada, controle da cobertura do solo - manejo de plantas espontâneas, manejo da palhada, aporte de restos culturais, entre outras (Figura - Propriedade Rural da família Frantz).

Assim, esse sistema de produção está sendo desenvolvido em nove áreas de lavoura e três áreas de pomar, totalizando 5,39 hectares. Essas áreas estão distribuídas conforme a Figura 1. 
Agroecologia: experiência em construção no contexto do Desenvolvimento Regional

Figura 1 - Localização da Propriedade

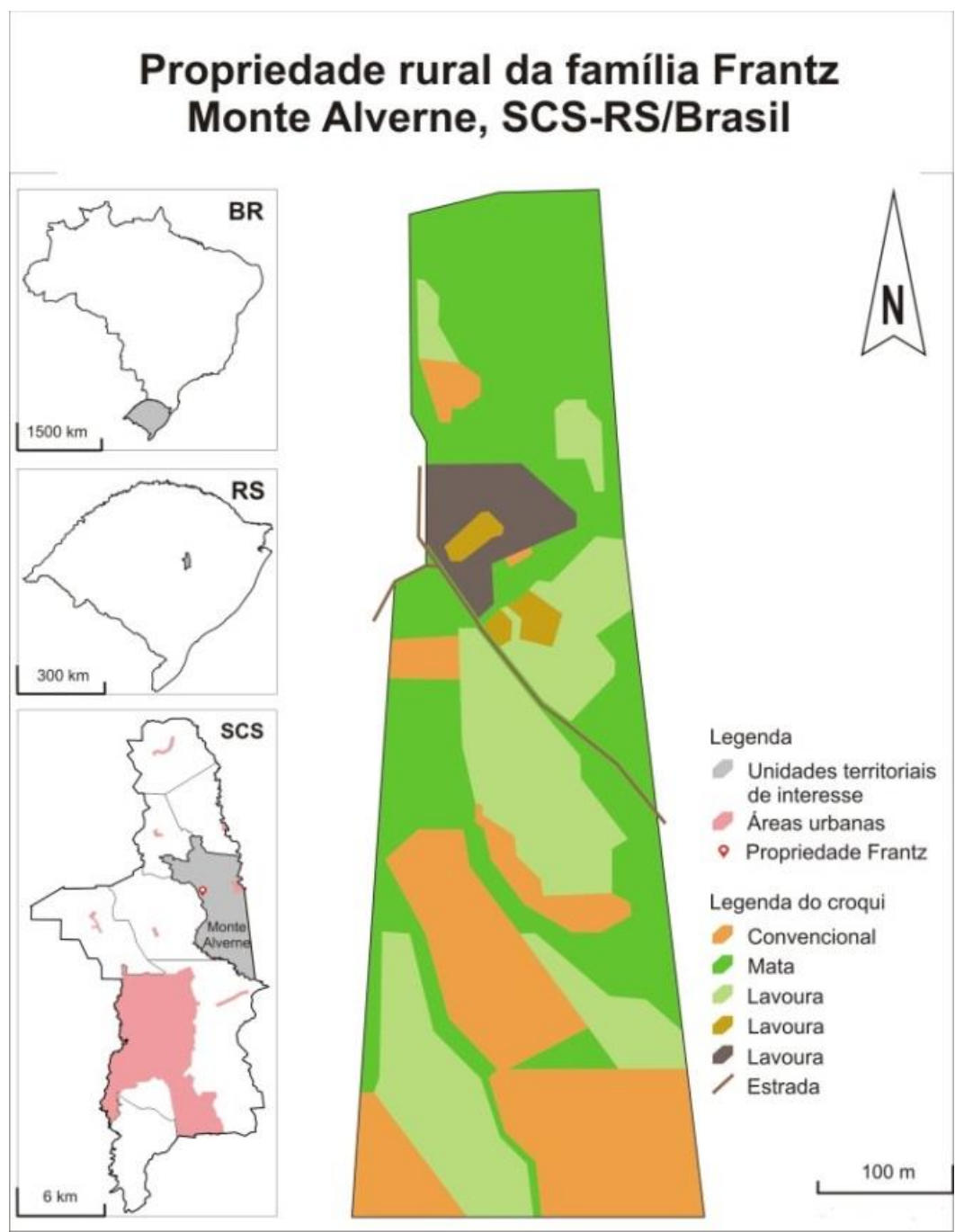

Fonte: Jaime Weber, 2019 


\section{Figura 2 - Produção de banana na propriedade}

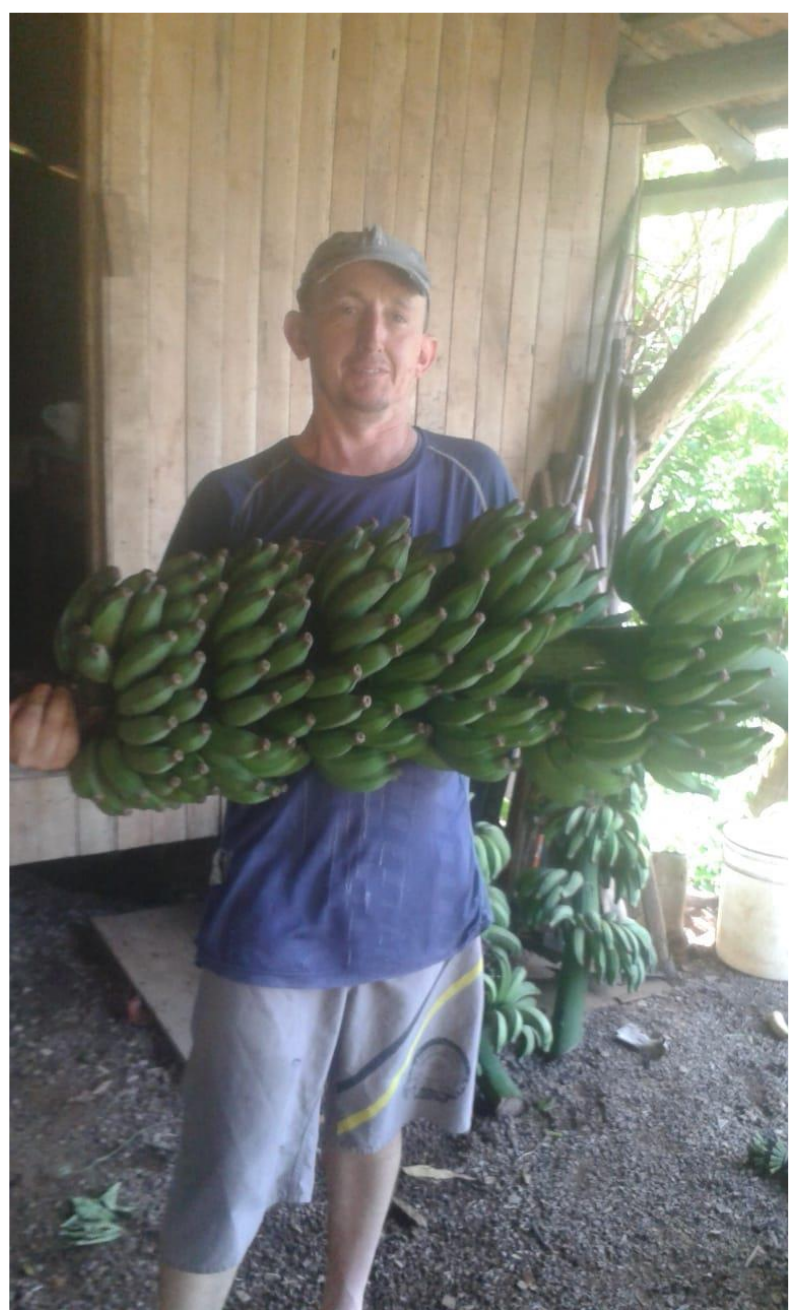

Fonte: Jaime Weber, 2019

Uma das inovações a partir de 2018, e intensificada em 2019, foi a consorciação de banana com citros. Esta inovação foi motivada pela observação do comportamento de capim-elefante ou capim cameroon (Pennisetum purpureum), que já existia numa parte do pomar com o objetivo de isolar o pomar, e este capim elefante tinha uma relação benéfica com a fileira de plantas de citros que estavam próximas. A observação empírica motivou o agricultor a buscar alternativas para resolver alguns limites do sistema de produção: o pomar de citros precisava de uma proteção dos ventos frios do inverno, e uma proteção (sombreamento) para as frutas do excesso de calor no verão e de isolamento da área. O capim elefante funcionou bem para a proteção das plantas no inverno, e também proporcionou um sombreamento interessante para as frutas no verão a partir das folhas secas, onde as frutas ficavam protegidas e proporcionavam uma maior longevidade nas plantas. Esta observação motivou a instalação da consorciação de banana com citros, em substituição ao capim elefante, para obter uma vantagem adicional. Ou seja, além da banana realizar a função de proteção para os citros, há a possibilidade de ampliar a produção de banana e dos citros. 
Assim, com o manejo da banana no inverno - corte e limpeza da parte aérea - é possível garantir uma quantidade de luz suficiente para os citros, e no verão, a banana se recupera e produz normalmente, e ainda protege os citros com o sombreamento parcial ou meia sombra. A longevidade da fruta na planta de citros proporciona um melhor rendimento econômico. Esse tipo de manejo permite uma colheita antecipada do citros no inverno, e no verão, é possível ter uma colheita mais prolongada. Para Perci, essa combinação ou consorciação é bastante benéfica, porque os há também um melhor aproveitamento e disponibilização de nutrientes para os dois cultivos, considerando que alguns nutrientes que faltam para o citros, podem ser disponibilizados pela banana. Então, o manejo de plantas espontâneas, a cinza que é utilizada de tempos em tempos, a implantação de linhas de banana intercaladas com o citros, e o desenvolvimento natural do piolho de cobra nesse sistema, são as apostas para melhorar o equilíbrio das plantas e a produção. Além dessas estratégias de manejo, o agricultor pretende adaptar as podas de limpeza dos citros e o manejo das plantas de banana para facilitar a proteção dos ventos e o excesso de calor.

\section{c) Manejo do solo}

O manejo do solo, antes do início da produção ecológica, seguia a mesma prática (antiga) utilizada na região: desmatamento, preparo do solo e plantio, degradação pelo uso intensivo do solo, "abandono" para a recuperação, e novo plantio. Essa é uma prática utilizada na região, especialmente para áreas com declive acentuado que se degradam com facilidade. Com o início da produção, considerada como um processo de transição do convencional para o ecológico, foi possível perceber as mudanças na qualidade do solo, com aumento crescente e significativo na produtividade.

Uma das mudanças percebidas no manejo da palha da bananeira foi o aparecimento do piolho de cobra. No princípio, o aparecimento do piolho de cobra foi visto como suspeita de um problema para a produção. Observando o comportamento do piolho de cobra, associado ao ambiente úmido e de boa palhada, foi possível constatar que a produção de húmus estava sendo incrementada de forma rápida e, consequentemente, a condição de fertilidade do solo melhorava visivelmente. Com a busca de informação sobre o piolho de cobra ficou evidente que se tratava de um "triturador" de detritos e de matéria vegetal morta, e que acelera de forma rápida a decomposição do material que fica na superfície do solo transformando-o em húmus. 0 piolho de cobra tem uma boa adaptação nesse tipo de manejo em que a palha fica no solo como cobertura morta e serve de alimento para o piolho de cobra que se multiplica de forma razoável, além de outros microrganismos do solo que também são beneficiados com esse tipo de manejo. Dessa forma, acelera a decomposição da matéria orgânica com um incremento razoável de húmus no solo, e contribui para a recuperação do solo (equilíbrio) e aumento da produção, com baixíssima incidência de doenças. "O piolho de cobra produz os nutrientes que as plantas necessitam e reequilibram o sistema", afirma Perci. 
No pomar de citros se percebe um controle excelente de doenças e da mosca da fruta. As doenças são controladas pelo equilíbrio nutricional das plantas com o manejo do solo e limpeza das plantas, e ainda com a aplicação de biofertilizante e calda a base de enxofre. O controle da mosca da fruta é realizado com a utilização de iscas de solução proteica (melado, vinagre e água 2 colheres de sopa de melado, 1 litro de água, 1 colher de chá de vinagre - duração de 2 meses em média, na sombra) que atraem a mosca; os frascos dessas iscas são preparados a partir da reciclagem de garrafas pet. A calda sulfocálcica (enxofre) é um repelente da mosca, acredita Perci.

\section{Figura 3 - Produção de laranja na propriedade}

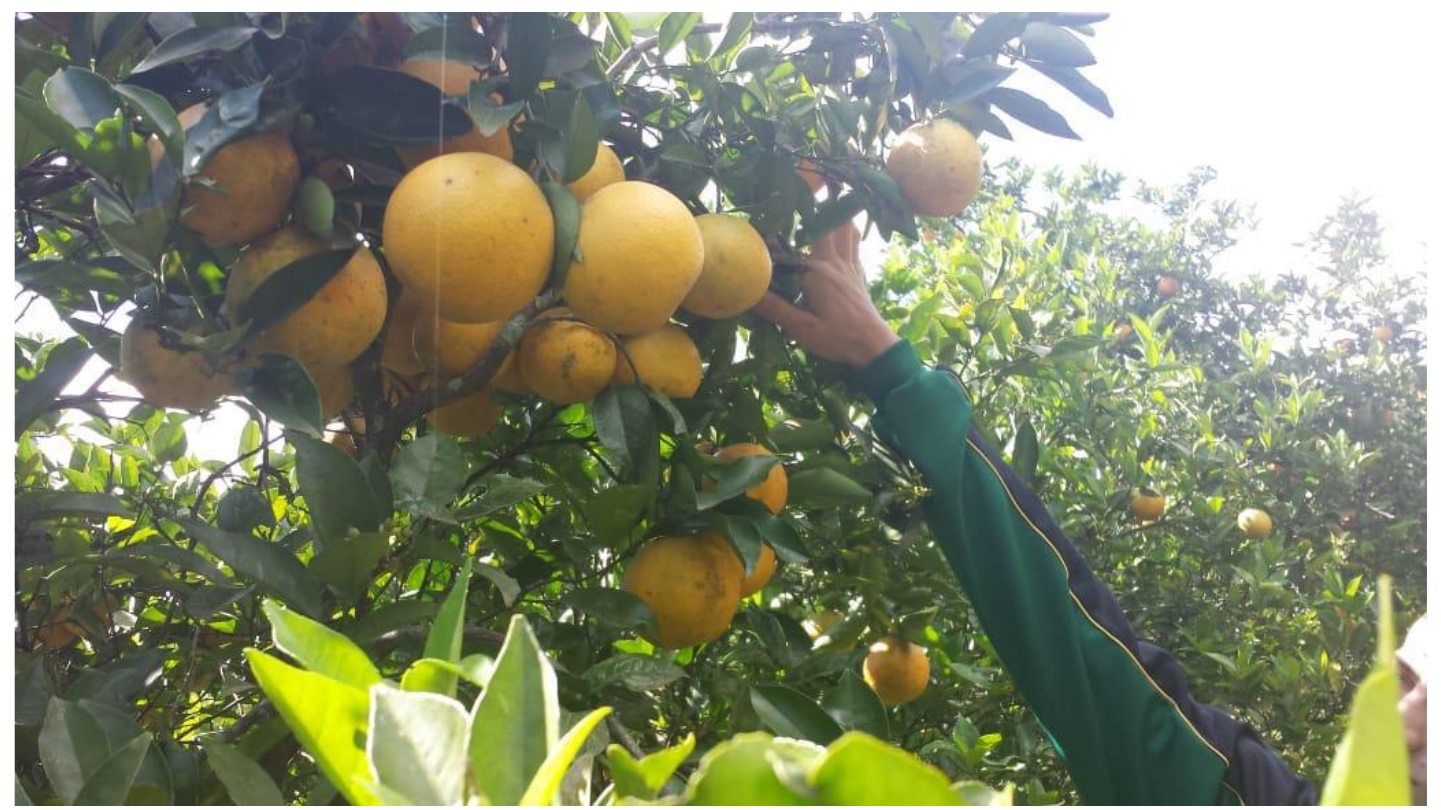

Fonte: Jaime Weber, 2019

d) Relações familiares

Há que se destacar que essas tentativas de produção ecológica não eram bem vistas e compreendidas pela família e pela comunidade. Tratava-se quase de uma aventura pelo fato de não haver experiência semelhante na comunidade. Na época, Perci sentia-se "solitário" para uma empreitada com tamanho desafio. Atualmente, esse tema é tratado com certa naturalidade e com maior compreensão sobre a preocupação da família e da comunidade, "eles não acreditavam que seria possível viabilizar economicamente a produção de frutas em 5,39 ha, sem a utilização de adubos químicos solúveis e agrotóxicos", pondera Perci, e acrescenta, "a minha convicção era maior que a dúvida deles".

e) Produção: início e transição

No início do processo de conversão/transição do sistema convencional para o de base ecológica os custos foram mais elevados, principalmente em função da mão de obra. Com o tempo e com o manejo adequado esse custo foi diminuindo. Atualmente o 
custo está em aproximadamente um terço do custo inicial. Nessa área de 5,39 hectares o trabalho é realizado num formato adaptado de sistema agroflorestal. Quando assumiu - pomar de citros da família, através de arrendamento, a produção era de aproximadamente 30 toneladas por ano, com o processo de transição foi possível chegar a 70 toneladas/ano.

A produção de banana também teve uma evolução muito boa na produção e produtividade. A implantação do bananal foi sendo realizada de forma gradativa, a medida que que as áreas foram sendo disponibilizadas, isso significa que as áreas não são contíguas e, segundo o Perci, os espaçamentos utilizados são diferenciados em cada área, com o propósito de avaliar (testar) o que pode ser mais adequado para aquele agroecossistema. As mudas de banana foram retiradas de um bananal existente na propriedade há mais de 20 anos, mesmo correndo o risco de levar a doença conhecida como "mal do panamá" para essas áreas novas. Atualmente a área de 2,62 ha produz em torno de 35 toneladas/ano. No início a produção de banana teve um custo elevado, hoje esse custo é em torno de 1/3 comparado com o custo inicial.

Dessa forma, além da excelente resposta obtida no sistema de produção (equilíbrio), especialmente com citros e banana, e com uma redução significativa nos custos, a produção atual é de aproximadamente 105 toneladas de frutas por ano.

f) Comercialização

Perci ressalta que no início a comercialização foi bastante complicada por vários fatores como:

- Falta de apoio: As instituições e organizações nem sempre compreendem e apoiam processos que estão em construção;

- Aparência do produto: no início, e com o desequilíbrio do sistema de produção não se consegue ter uma produção uniforme e de boa aparência;

- Falta de conhecimento sobre o mercado: dificuldade de conhecer e entender as dinâmicas dos distintos mercados (mercados pequenos e médios, supermercados, fruteiras, entre outros), e as possibilidades de comercializar de forma regular;

- Relação de confiança: cada tipo de mercado é uma conquista, e estabelecer uma relação de confiança é fundamental para ter segurança e garantia para se manter no mercado. Essa relação de confiança com os proprietários dos mercados e com o consumidor (saber o que o consumidor prefere) é fundamental para conquistar e se manter no mercado.

O consumidor tem que gostar do produto, e aí entra a grande vantagem do produto ecológico que se diferencia no mercado, especialmente pelo sabor e pela durabilidade. Outra questão relevante expressada por Perci, e que se reflete positivamente na produção de frutas nesse ambiente de mata atlântica, é a possibilidade de antecipar a venda entre 30 e 45 dias, o que confere uma melhor renda pelo fato de entrar no mercado antes do início normal da safra. 
A produção de base ecológica tem demostrado, a partir da observação empírica do agricultor, que quanto mais equilíbrio se consegue no sistema de produção, maior é o período de produção, as floradas ficam vigorosas, os frutos ficam resistentes ao ataque de doenças e insetos (cascas mais espessas e resistentes), os frutos permanecem por um período maior na planta, e a produção de frutas "temporonas" (fora de época) é significativa e de boa qualidade, o que possibilita a comercialização de frutas póscolheita, e com elevação do valor da fruta.

Mesmo tendo mercado para tudo o que é produzido, um limite enfrentado é a comercialização como produto orgânico que era de apenas 5 \% até 2018, em 2019 em torno de 15 a $20 \%$ do volume produzido, em função da dificuldade de custear a certificação de por auditoria.

Atualmente, o maior volume comercializado acontece através de duas cooperativas, a Coopersanta de Santa Cruz do Sul/RS, e a Cooprova de Venâncio Aires/RS. Estas duas cooperativas comercializam com as escolas destes municípios, através do programa da merenda escolar. A merenda escolar é sem dúvida uma opção importante de comércio das frutas. Os principais produtos comercializados para essas duas cooperativas são a laranja, a bergamota, a banana e o chuchu. Além dessas cooperativas, alguns mercados e restaurantes de Santa Cruz do Sul e Vera Cruz também estão absorvendo parte da produção. A empolgação demonstrada é tamanha que a questão econômica é tratada muito mais como viabilidade de manter o sistema e se manter na atividade, do que ganhar dinheiro. No entanto, não fica difícil comprovar a viabilidade econômica desse sistema de produção, considerando os patamares de produtividade e o preço dos produtos que esse tipo de sistema de produção proporciona.

\section{g) Certificação}

Desde 2015 Perci participa da Rede Ecovida de Agroecologia que é pioneira no desenvolvimento da certificação participativa, metodologia de verificação da conformidade, hoje também conhecida como Sistema Participativo de Garantia. Em se tratando de certificação, e para atender a demanda de comercialização de 105 toneladas por ano, avalia que apesar de ter uma produção de base ecológica há alguns limites para a comercialização, em relação a legislação para a produção de orgânicos, em função de que boa parte da sua produção não é comercializada de forma direta. Avalia ainda que a possibilidade de comercializar seus produtos com certificação pode render um pouco mais, mas funcionará principalmente como uma espécie de marketing para esse nicho de mercado que ainda é pouco conhecido e reconhecido pela sociedade.

h) Estrutura para o sistema de produção

Para atender a produção, transporte e comercialização nessa área física de 6,5 hectares, o agricultor possui uma estrutura básica composta de: - Câmara de amadurecimento para as frutas: essa câmara foi construída/adaptada pelo próprio 
agricultor e para acelerar o processo de maturação é utilizado um hormônio natural; Veículos: uma caminhonete corsa ano 1998 que é utilizada para a movimentação e transporte (frutas e equipamentos) dentro da propriedade, e também na comunidade. Recentemente foi adquirida uma sprinter, ano 2010, que está sendo utilizada para levar as frutas para o comércio de Santa Cruz do Sul, Vera Cruz e Venâncio Aires; Equipamentos: duas roçadeiras costais para fazer o controle das plantas - roçada para cobertura do solo e produção de matéria orgânica. Outros equipamentos comuns também são utilizados para o manejo das plantas, como pá, enxada, ancinho e um atomizador que é utilizado para a aplicação de biofertilizante e de caldas; um equipamento foi criado/adaptado para o manejo nas bananeiras; - Estrutura física: uma câmara de maturação $(3,0 \times 2,70 \mathrm{~m})$, uma estrutura de $13 \times 4$ metros que abriga um pequeno escritório, e garagem para os carros. Em dias de chuva essa área coberta das garagens é utilizada para manejar a frutas (classificação e embalagem) para o comércio.

i) Percepção sobre saúde

Perci demonstra uma grande preocupação com a saúde da população. Enfatiza que o agricultor não deve se preocupar demasiadamente com a questão econômica da produção; a saúde e o modo de vida devem ser levados em conta. O uso de agrotóxicos pode e deve ser diminuído. Expressa sua satisfação em poder oferecer um produto equilibrado e de qualidade biológica para o consumidor, especialmente para as crianças, através do programa de alimentação escolar. "o meu consumidor pode comer tranquilo", e conclui dizendo que alimento equilibrado gera saúde equilibrada.

j) Avaliação/lições/limites

Perci afirma que a produção de alimentos com base nos princípios da agroecologia é perfeitamente possível e viável; e aponta para a perspectiva de que essa forma de produzir pode garantir a sobrevivência da agricultura familiar e a produção de alimentos para a população mundial. Pela sua experiência prática já é possível afirmar que a produtividade da produção de base ecológica pode chegar aos mesmos patamares da produção convencional, com a vantagem do custo reduzido.

Para efeito deste trabalho iremos tratar da agricultura de base ecológica para caracterizar a experiência que será relatada, mas também para algumas situações utilizaremos o termo agricultura orgânica, especialmente quando trataremos da legislação de orgânicos. Segundo Meirelles (2003), vem crescendo a percepção que adjetiva como 'orgânica' aquela agricultura que busca a produção de alimentos limpos para um mercado diferenciado, e de 'ecológica' a configuração de trabalhar um modo de agricultura que visa um redimensionamento da relação do ser humano com a natureza e com o outro, com referências mais harmônicas e solidárias, em que o mercado não seja um fim em si mesmo.

Um dos limites apresentados pelo agricultor é a falta de tempo para se dedicar em experimentos na propriedade e para buscar mais informações técnicas (pesquisas e outras experiências) que possam contribuir para qualificar seu sistema de produção. 


\section{Experiência no contexto da produção sustentável}

Nas conversas e entrevistas realizadas com o agricultor percebe-se o entusiasmo em relação ao conhecimento produzido e os resultados alcançados desde o início da produção. Por outro lado, parece haver dúvida sobre a denominação ou conceituação para esse sistema de produção. Confrontando a experiência realizada na propriedade, relatada anteriormente, com as teorias existentes pode-se deduzir que se trata de uma experiência de agricultura de base ecológica, mesmo que ainda esteja num processo de transição.

O sistema é manejado com base nos princípios da agroecologia, com a busca permanente de harmonização das condições ecológicas, socioculturais e econômicas, com o fortalecimento do desenvolvimento endógeno compreendido como o desenvolvimento local, produzido por esse agricultor, numa relação assentada nos recursos locais. Trata-se de determinar localmente as opções e o controle sobre os processos de mudanças, incluindo a iniciativa e a autonomia sobre a geração de novos conhecimentos, práticas e produtos. Dessa forma, há um reconhecimento e satisfação sobre outra forma de trabalhar na agricultura e de viver de forma harmônica no espaço rural.

A busca de sistemas agrícolas autossustentáveis, com baixo uso de insumos externos, diversificados e eficientes em termos energéticos, é a maior preocupação dos pesquisadores, agricultores e formuladores de políticas públicas em todo o mundo (ALTIERI, 1998, p. 59). É uma experiência territorial e não setorial de trabalhar um sistema de produção e suas relações com o território através do conhecimento gerado, das relações entre os atores, e da oferta de alimentos num circuito territorial de curtas distâncias e de baixo consumo energético.

\section{Desenvolvimento de tecnologias associadas ao sistema de produção}

Os agricultores estão constantemente buscando informações, adaptando e incorporando tecnologias, e desenvolvendo experiências, normalmente por conta própria, e dessa forma construindo, adaptando e desenvolvendo o conhecimento tradicional, compartilhado entre gerações, assim como os cientistas/pesquisadores também vêm desenvolvendo tecnologias e experiências ao longo dos tempos. Contudo, parece repetitivo, mas a potencialização desse trabalho empírico e científico seria ampliada e traria mais benefícios se houvesse maior proximidade entre esses atores. Cabe salientar que cientistas e agricultores são apenas dois dos grupos de distintos atores que fazem parte de um complexo e amplo sistema de geração e socialização de conhecimento. Além desses atores, também estão envolvidos nesse sistema de produção de conhecimento a extensão rural, os colégios e a universidades. 
A pesquisa científica envolve a observação, a identificação, a investigação e o desenvolvimento de explicações teóricas dos fenômenos naturais, ou das respostas da natureza a partir da ação humana. $O$ agricultor, a partir dos experimentos empíricos que realiza na propriedade, desenvolve e ou adequa técnicas e insumos que possam funcionar para seu sistema de produção, o que em tese já seria suficiente, mas possui dificuldade para entender o princípio científico e o potencial dessas experiências tornarem-se massivas e aplicáveis para outras situações. Quando se pensa em reprodução e divulgação de uma experiência exitosa há que se levar em conta a eficiência e eficácia dessa experiência para outros sistemas de produção. Parece que nesse ponto a pesquisa científica desenvolve uma função relevante para a sociedade, assim como os outros atores que atuam nas atividades rurais.

Para que haja essa aproximação entre pesquisadores e agricultores e para que se estabeleça uma comunicação efetiva é necessário o entendimento sobre o esforço de tornar sustentável e prazeroso o seu modo de vida, entender como funcionam aos estabelecimentos da agricultura familiar (sistema de produção), as relações familiares e comunitárias, o desenvolvimento histórico e suas causas e efeitos, o uso de recursos, o processo de tomada de decisões, as estratégias e prioridades, questões mercadológicas, os principais limites e as expectativas. Enfim, há necessidade de um conhecimento que transcende as questões técnicas (especialidades) e econômicas. A agricultura não é apenas uma coleção de cultivos agrícolas e de animais, trata-se de um complexo sistema que possui uma infinidade de relações e que, além de sofrer consignações provindas da situação biofísica, é determinada também por suas características socioculturais, econômicas, ambientais e políticas.

$\mathrm{Na}$ agronomia e na agricultura convencional a população de plantas cultivadas ou o número de animais de criação é o centro da atenção. Um produtor tenta maximizar o desempenho dessa população manejando os vários fatores do complexo ambiental. Contudo, quando a sustentabilidade de todo o agroecossistema é a prioridade, esse foco estreito sobre as necessidades de uma população geneticamente homogênea torna-se totalmente inadequado (GLIESSMAN, 2000, p. 343).

Para Gliessman (2000) há necessidade de se considerar os processos de interação entre populações que se estabelecem em nível de comunidade e de ecossistema. E nesse sentido que se pretende analisar a experiência relatada nesse ensaio, como uma ação exitosa que pode ser potencializada considerando os aspectos sistêmicos de produção e produtividade, de segurança, de continuidade e de identidade. Essa análise não pretende desenvolver avaliações de caráter científico e de mérito, mas apenas socializar uma experiência de um sistema de produção que tem logrado êxito ao longo dos anos, e tem como referência os princípios da agroecologia. Considerar e valorizar esse tipo de experiência praticada por agricultores parece ser o mínimo de compromisso da sociedade.

\section{Considerações finais}


Tendo em vista o atual quadro de destruição ambiental e de problemas sociais, a partir da década de 1970, os resultados da aplicação das estratégias convencionais de desenvolvimento já começavam a se mostrar insuficientes para dar conta das crescentes condições de desigualdades e de exclusão social. A sustentabilidade do planeta está em risco e tende a se agravar com o passar dos anos. Reconhecer, valorizar e dar visibilidade às experiências sustentáveis pode significar um passo à frente na responsabilidade com a atual geração, mas especialmente com as gerações futuras.

A transição de uma agricultura convencional para ecológica norteia-se em um processo gradual de mudança, através do tempo, nas formas de manejo dos agroecossistemas, tendo como meta a passagem de um modelo agroquímico de produção a um modelo ou estilo de agricultura que incorpore princípios, métodos e tecnologias com base ecológica. Os novos paradigmas de produção, que levem em conta o correto manejo dos recursos naturais, o desenvolvimento de sistemas mais autônomos e resilientes, a eficiência energética e os alimentos com qualidade biológica, a implementação de circuitos curtos entre produção e consumo, a solidariedade, a cidadania, entre outros fatores, podem representar uma nova forma de entendimento sobre a vida e, sobretudo, de vida com qualidade.

Por fim, a agricultura de base ecológica pode oferecer múltiplas soluções aos problemas do meio ambiente, econômicos e sociais. A eficácia e o sucesso de um desenvolvimento sustentável dependerão não somente de condições de produção, marketing e organização, mas, sobretudo, do compromisso dos agricultores e o design da região programada e planejada. Com o objetivo de assegurar um desenvolvimento independente e duradouro nas áreas rurais muito tem que ser feito no futuro. Um desenvolvimento projetado e planejado é fundamental para o crescimento com sucesso da agroecologia. Isto inclui não somente colaboração na produção, marketing e lobby político, mas também cooperação na pesquisa.

A experiência analisada neste artigo representa uma entre tantas que se multiplicam no Brasil e no mundo, e que podem servir de referência para ampliar quantitativamente e qualitativamente as experiências concretas de produção com base nos princípios da agroecologia.

\section{Referências}

ALTIERI, M. Agroecologia: a dinâmica produtiva da agricultura sustentável. Porto Alegre. Ed. Universidade/UFRGS, 1998.

CAPORAL, F. R.; COSTABEBER, J. A. Agroecologia: alguns conceitos e princípios (2004). Disponível em http://www.planetaorganico.com.br/trabCaporalCostabeber.htm. Acessado em 28 de ago. 2018.

DELGADO, G. C., BERGAMASCO, S. M. P. P. (orgs.). Agricultura familiar brasileira: desafios e perspectivas de futuro. Brasília: Ministério do Desenvolvimento Agrário, 2017. 
Agroecologia: experiência em construção no contexto do Desenvolvimento Regional

ELIAS, D. Relações campo-cidade. Texto para o Seminário: Relações Campo-Cidade, Reestruturação Urbana e Regional no Brasil, 2012. Disponível em www.ub.edu/geocrit/coloquio2012/actas/07-D-Elias.pdf. Acessado em 27 ago. 2018.

GLIESSMAN, S. R. Agroecologia: processos ecológicos em agricultura sustentável. Porto Alegre. Editora universidade/UFRGS, 2000.

GLIESSMAN, S. R. Sustainable agriculture: an agroecological perspective. Advances in Plant Pathology, v.11, p.45-57, 1995.

KARNOPP, Erica. Kleinbauern zwischen konventioneller und ökologischer Landwirtschaft: das Beispiel der Region Vale do Rio Pardo Brasilien). Tese de Doutorado. Tübingen, 2004.

MEIRELLES, L. A Certificação de Produtos Orgânicos - caminhos e descaminhos. Ipê, RS, 2003.

PETERSEN, P., MUSSOI, E.M., DAL SOGLIO, F. Institutionalization of the Agroecological Approach in Brazil: Advances and Challenges. 2013

VEIGA, J. E. O Brasil Rural Ainda não Encontrou seu Eixo de Desenvolvimento. (2001). Disponível em http://www.scielo.br/pdf/ea/v15n43/v15n43a10.pdf. Acessado em 27 de ago. 2018.

Sobre os autores:

Erica Karnopp, Doutora em Geografia (Universität Tübingen-Alemanha). Professora da Universidade de Santa Cruz do Sul - UNISC. E.mail: erica@unisc.br

Jaime Miguel Weber, Engenheiro Agrônomo, Doutorando em Desenvolvimento Regional na Universidade de Santa Cruz do Sul - UNISC, Bolsista CAPES 1. E.mail: jaimeweber1@hotmail.com 